\title{
Controlled Single and Double lodofluorination of Alkynes with DIH- and HF-based Reagents
}

\author{
Lukas Pfeifer and Véronique Gouverneur*
}

Chemistry Research Laboratory, University of Oxford, Mansfield Road, Oxford, OX1 3TA, U.K. Supporting Information Placeholder

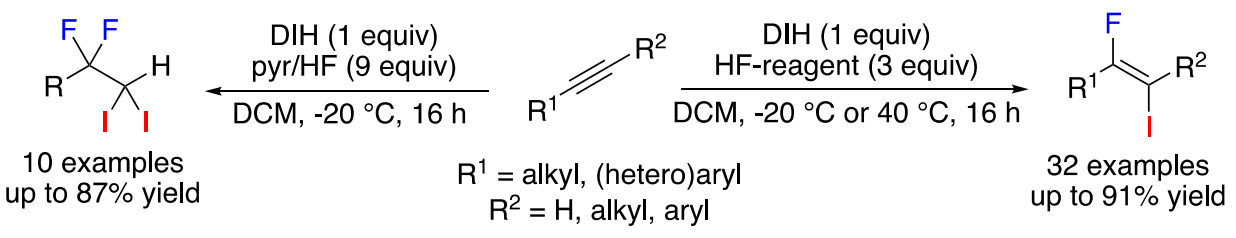

\begin{tabular}{l}
\hline ABSTRACT: A novel protocol for the regio- and stereoselective iodofluorination of internal and terminal alkynes using 1,3- \\
diiodo-5,5,-dimethylhydantoin and HF-based reagents is disclosed. This approach is used to prepare a fluorinated tamoxifen \\
derivative in two steps from commercially available starting materials. A facile method enabling controlled regioselective \\
double iodofluorination of terminal alkynes is also presented.
\end{tabular}

A classical strategy for the halofluorination of alkynes uses electrophilic halogenating reagents in combination with sources of HF. ${ }^{1}$ These methods are typically associated with low yields, ${ }^{\text {1c,e,f }}$ poor selectivity ${ }^{\text {ld-f }}$ as well as a substrate scope restricted to unfunctionalized hydrocarbons. ${ }^{1, f}$ These limitations have prompted the use of alternative reagents such as hypervalent iodine species. ${ }^{2}$ These reactions that proceed via the formation of $(E)$-(fluoroalkenyl)iodonium fluorides, ${ }^{2 b}$ suffer from by-product formation for terminal alkyne substrates. ${ }^{2 \mathrm{C}}$ Rozen and co-workers reported the addition of $\mathrm{BrF}$ and IF, generated from the elements, to unfunctionalized alkynes, leading to the formation of stereoisomeric mixtures, and in some cases, uncontrolled single and double addition products. 3 Isolated examples of iodofluorination of 3-hexyne employing bis(pyridine)iodonium tetrafluoroborate and fluoride salts, ${ }^{4}$ or a combination of elemental iodine and $\mathrm{XeF}_{2}$, have also been disclosed. ${ }^{5}$ In quest of a reliable simpler protocol, the cis-bromofluorination of terminal alkynes using $N$-bromosuccinimide and an excess of AgF was developed by Jiang, ${ }^{6}$ and Hara reported the iodofluorination of internal and terminal alkynes using $\mathrm{IF}_{5^{-}}$ pyridine-HF.7 From this survey, it is apparent that the development of a regioselective iodofluorination method compatible with functionalized alkynes and using easily accessible reagents is still highly desirable.

Given our interest in transition metal mediated C-F bond formation, ${ }^{8}$ our initial approach considered Au-catalysis to activate the alkyne. Hashmi ${ }^{9}$ reported that an alkenyl-Au(I) species can undergo halodeauration when treated with an electrophilic halogen source, and Sadighi ${ }^{10}$ demonstrated that internal alkynes reversibly form $\beta$-(fluorovinyl)gold(I) complexes in the presence of $[\mathrm{Au}(\mathrm{SIPr}) \mathrm{F}]$.
Building on these precedents, a preliminary experiment consisted of adding $N$-bromosuccinimide (NBS) to the equilibrium mixture of 3 -hexyne and $\beta$-(fluorovinyl)gold(I) complex 1; this reaction led to $32 \%$ of $(E)$-3-bromo-4-fluorohex-3-ene, 2, and $15 \%$ of (Z)-3-fluorohex-3-ene, 3 (Scheme 1a), being formed. The treatment of the preformed gold(I)-alkyne $\pi$-complex 4 with NBS and either $\mathrm{NEt}_{3} \cdot 3 \mathrm{HF}$ or $\left(\mathrm{Me}_{2} \mathrm{~N}\right)_{3} \mathrm{~S}(\mathrm{Me})_{3} \mathrm{SiF}_{2}$ (TASF) gave 2 in $18 \%$ and $64 \%$ yield, respectively (Scheme $\mathrm{ib}$ ).

Scheme 1. Au-mediated bromofluorination of alkynes.

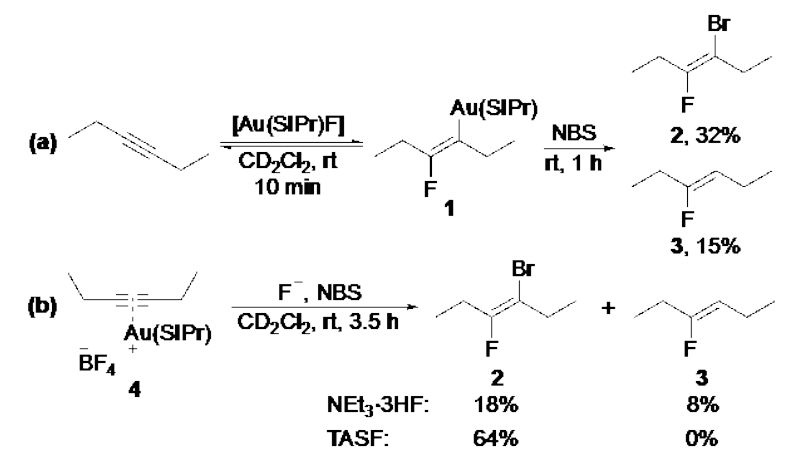

These results encouraged further investigation. The reaction of 3-hexyne with NBS in the presence of $\left[\mathrm{Au}(\mathrm{SIPr}) \mathrm{BF}_{4}\right]$ $(5 \mathrm{~mol} \%)$ led to no (TASF) or only traces $\left(\mathrm{NEt}_{3} \cdot 3 \mathrm{HF}\right)$ of bromofluorinated product (Table 1, entries 1 and 2 ). The replacement of NBS with 1,3-dibromo-5,5,-dimethylhydantoin (DBH) afforded the desired product in $54 \%$ yield, and a control experiment revealed that $\mathbf{6 a}$ was also formed in the absence of Au-catalyst (Table 1, entries 3 and 4). Screening of alternative sources of fluoride, electrophilic bromine sources and solvents identified $\mathrm{NEt}_{3} \cdot 3 \mathrm{HF}$ and $\mathrm{DBH}$ in DCM as optimum for this reaction (Table 1, entries 5-7; Tables 
$\mathrm{S}_{2}-\mathrm{S}_{5}$ ). Only HF-based reagents were effective (Table $\mathrm{S}_{2}$ ). By lowering the temperature to $0{ }^{\circ} \mathrm{C}$ (Table 1 , entry 8 ) and increasing the amount of $\mathrm{NEt}_{3} \cdot 3 \mathrm{HF}$ to 3 equiv (Table 1, entries 9 and 10 ), 6 a was isolated in $80 \%$ yield but as a mixture with $15 \%$ of $(E)$-5,6-dibromodec-5-ene, which could not be separated by silica gel chromatography (Conditions A). DMPU/HF was not satisfactory for this reaction (Table 1 , entry 11)." ${ }^{11}$ When using 1,3-diiodo-5,5,-dimethylhydantoin (DIH) instead of DBH, the reaction was best performed using $\mathrm{NEt}_{3} \cdot 3 \mathrm{HF}$ at $4 \mathrm{O}^{\circ} \mathrm{C}$ and gave $(E)-5$-fluoro-6-iododec-5ene, $7 \mathrm{a}$, isolated pure in $91 \%$ yield (Conditions B) (Table 1 , entries 12-14; Table S6).

Table 1. Optimization of halofluorination of $\mathbf{5} \mathbf{a}$.

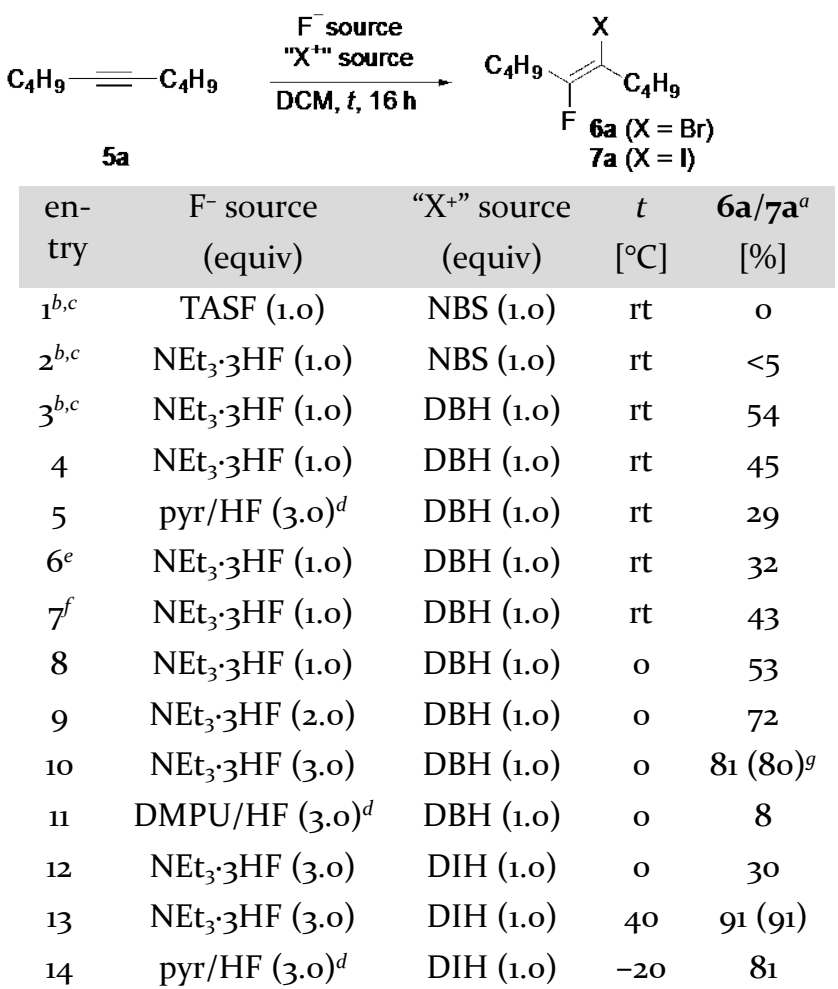

${ }^{a}$ Determined by ${ }^{1} \mathrm{H}$ and ${ }^{19} \mathrm{~F}$ NMR of crude reaction mixture (1fluoro-3-nitrobenzene as internal reference). Isolated yields in parentheses. ${ }^{3} 3$-Hexyne is used as substrate affording bromofluorinated alkene 2. "With $5 \mathrm{~mol} \%$ of $\left[\mathrm{Au}(\mathrm{SIPr}) \mathrm{BF}_{4}\right]$. ${ }^{\mathrm{d}}$ Equiv HF. In DCE. ${ }^{\mathrm{f} I n} \mathrm{CHCl}_{3}$. Is Isolated in a mixture with $15 \%$ of $(E)$ 5,6-dibromodec-5-ene.

These conditions applied to the terminal alkyne 1hexyne 8a afforded the iodofluoroalkene 9a in $35 \%$ yield as a single diastereomer (Table 2 , entry 1 ). Increasing the amount of $\mathrm{NEt}_{3} \cdot 3 \mathrm{HF}$ or lowering the temperature had detrimental effects on the outcome of the reaction (Table 2 , entries 2 and 3). Switching to pyr/HF gave $14 \%$ of mono iodofluorinated 9 a along with $29 \%$ of double iodofluorinated 1oa (Table 2, entry 4). By lowering the temperature to $20{ }^{\circ} \mathrm{C}$, 9a could be isolated in $74 \%$ yield (Conditions C) (Table 2, entries 5 and 6). An increase of the amount of pyr/HF to 9 equiv led to the exclusive formation of double iodofluorinated product 1oa in $80 \%$ yield using 1 equiv of DIH (Conditions D) (Table 2, entry 7). This later transformation absorbs fully the iodine content of this reagent. ${ }^{12}$
Table 2. Optimization of selective single and double iodofluorination of terminal alkynes.

\begin{tabular}{|c|c|c|c|c|}
\hline $8 \mathbf{a}$ & $\begin{array}{c}\mathrm{F}^{-} \text {source } \\
\text { DHH (1 equiv) } \\
\mathrm{DCM}, t, 16 \mathrm{~h}\end{array}$ & $9 a^{F}$ & $10 \mathrm{a}$ & I \\
\hline entry & $\begin{array}{c}\mathrm{F}^{-} \text {source } \\
\text { (equiv) }\end{array}$ & $\begin{array}{c}\mathrm{t} \\
{\left[{ }^{\circ} \mathrm{C}\right]}\end{array}$ & $\begin{array}{l}\mathbf{9 a}^{a} \\
{[\%]}\end{array}$ & $\begin{array}{c}10 a^{a} \\
{[\%]}\end{array}$ \\
\hline 1 & $\mathrm{NEt}_{3} \cdot 3 \mathrm{HF}(3.0)$ & 40 & 35 & o \\
\hline 2 & $\mathrm{NEt}_{3} \cdot 3 \mathrm{HF}(5 \cdot 0)$ & 40 & 28 & o \\
\hline 3 & $\mathrm{NEt}_{3} \cdot 3 \mathrm{HF}(3.0)$ & $\mathrm{rt}$ & 31 & o \\
\hline 4 & $\mathrm{pyr} / \mathrm{HF}(3.0)^{b}$ & $\mathrm{rt}$ & 14 & 29 \\
\hline 5 & $\mathrm{pyr} / \mathrm{HF}(3.0)^{b}$ & $\mathrm{O}$ & 33 & 20 \\
\hline 6 & $\mathrm{pyr} / \mathrm{HF}(3.0)^{b}$ & -20 & $77(74)$ & 8 \\
\hline 7 & $\mathrm{pyr} / \mathrm{HF}(9.0)^{b}$ & -20 & $\mathrm{o}$ & $87(80)$ \\
\hline
\end{tabular}

a Determined by ${ }^{1} \mathrm{H}$ and ${ }^{19} \mathrm{~F}$ NMR of crude reaction mixture (1fluoro-3-nitrobenzene as internal reference). ${ }^{b}$ Equiv HF.

In this study, the difference in reactivity of the $\mathrm{DIH} / \mathrm{NEt}_{3} \cdot 3 \mathrm{HF}$ and $\mathrm{DIH} / \mathrm{pyr} / \mathrm{HF}$ systems is notable. It is known that halogenating reagents can be activated either with Brønsted and Lewis acids, or with nucleophilic promoters. Brønsted acid activation is more plausible for $\mathrm{DIH} / \mathrm{pyr} / \mathrm{HF}\left(\mathrm{p} K_{\mathrm{aH}}(\mathrm{pyr})=5.2\right)$ than for $\mathrm{DIH} / \mathrm{NEt}_{3} \cdot 3 \mathrm{HF}$ $\left(\mathrm{p} K_{\mathrm{aH}}\left(\mathrm{NEt}_{3}\right)=10.7\right) .^{13}$ In contrast, nucleophilic activation could be more effective for $\mathrm{DIH} / \mathrm{NEt}_{3} \cdot 3 \mathrm{HF}$ than $\mathrm{DIH} / \mathrm{pyr} / \mathrm{HF}$ considering the reduced hydrogen bond accepting potential of pyridine $\left(\mathrm{p} K_{\mathrm{BHX}}=1.86\right)$ versus $\mathrm{NEt}_{3}$ $\left(\mathrm{p} K_{\mathrm{BHX}}=1.98\right) . .^{14}$

Having established the optimum conditions for the iodofluorination of internal and terminal alkynes, we studied the substrate scope of these transformations. For internal alkynes (Scheme 2), conditions B (3 equiv of $\mathrm{NEt}_{3} \cdot 3 \mathrm{HF}$, $40{ }^{\circ} \mathrm{C}$ ) gave good to excellent yields for the iodofluorination of electron neutral as well as electron rich substrates $5^{\mathbf{a}} \mathbf{-}-\mathbf{5}$, $\mathbf{5 h}-\mathbf{5 j}, \mathbf{5 n}, \mathbf{5 s}$ and $\mathbf{5 u}$, with a lower yield of $26 \%$ for furan derivative $\mathbf{5 t}$. The $p$-Cl-substituted alkyne $\mathbf{5 g}$ gave almost identical yields with conditions $\mathrm{B}$ and $\mathrm{C}$ (pyr/HF, $-2 \mathrm{O}^{\circ} \mathrm{C}$ ). Conditions $\mathrm{C}$ were superior for the iodofluorination of electron poor substrates $\mathbf{5} \mathbf{d}-\mathbf{5} \mathbf{f}, \mathbf{5} \mathbf{k}-\mathbf{5} \mathbf{m}$ and $\mathbf{5 0 -} \mathbf{5 q}$. Overall, different functionalities, among them unprotected alcohols (7j) and carboxylic acids (7) as well as esters $(7 \mathbf{k})$, cyano groups (7o), ketones $(\mathbf{7} \mathbf{f})$ and aromatic halides $(\mathbf{7 g}, \mathbf{7 m}$ and 7q), are tolerated under these conditions. The ${ }^{19} \mathrm{~F}-{ }^{1} \mathrm{H}_{\text {alkyl }}$ coupling constants $<4 \mathrm{~Hz}$ for products derived from alkyl aryl alkynes served to determine the sense of regiocontrol of the reaction. $\alpha$-Ketoalkyne $5 \mathrm{r}$ also underwent regioselective iodofluorination using 4 equiv of $\mathrm{pyr} / \mathrm{HF}$ at $\mathrm{rt}$, affording $7 \mathbf{r}$ in $48 \%$ yield. ${ }^{15}$ The influence of electronics on regioselectivity was studied using the unsymmetrically substituted stilbene derivative 5q. Under conditions $C_{59}$ gave an inseparable mixture of the two regioisomers $7 \mathbf{q a}$ and $\mathbf{7 q b}$, which were obtained in a 1.7:1 ratio, favoring fluoride attack on the more electron rich position as confirmed by ${ }^{19} \mathrm{~F}-{ }^{1} \mathrm{H}$ heteronuclear NOE (HOESY) analysis. When placing a primary and a secondary carbon substituent on the triple bond (5u) a 2.6:1 ratio of regioisomers was obtained, favoring fluoride attack on the less sterically congested alkyne 
carbon..$^{16}$ The presence of a tertiary carbon substituent $(\mathbf{5} \mathbf{v})$ resulted in only a trace amount of product being formed under conditions $B$ or $C$. Both $5 \mathbf{a}$ and $\mathbf{5} \mathbf{b}$ underwent successful bromofluorination under conditions A. The iodofluorination of $\mathbf{5} \mathbf{a}$ was performed starting from $\mathbf{5 . 0 0} \mathrm{mmol}$ of alkyne giving $1.32 \mathrm{~g}$ (93\%) of $7 \mathbf{a}$, demonstrating the robustness of this protocol towards scale-up.

Scheme 2. Halofluorination of internal alkynes.

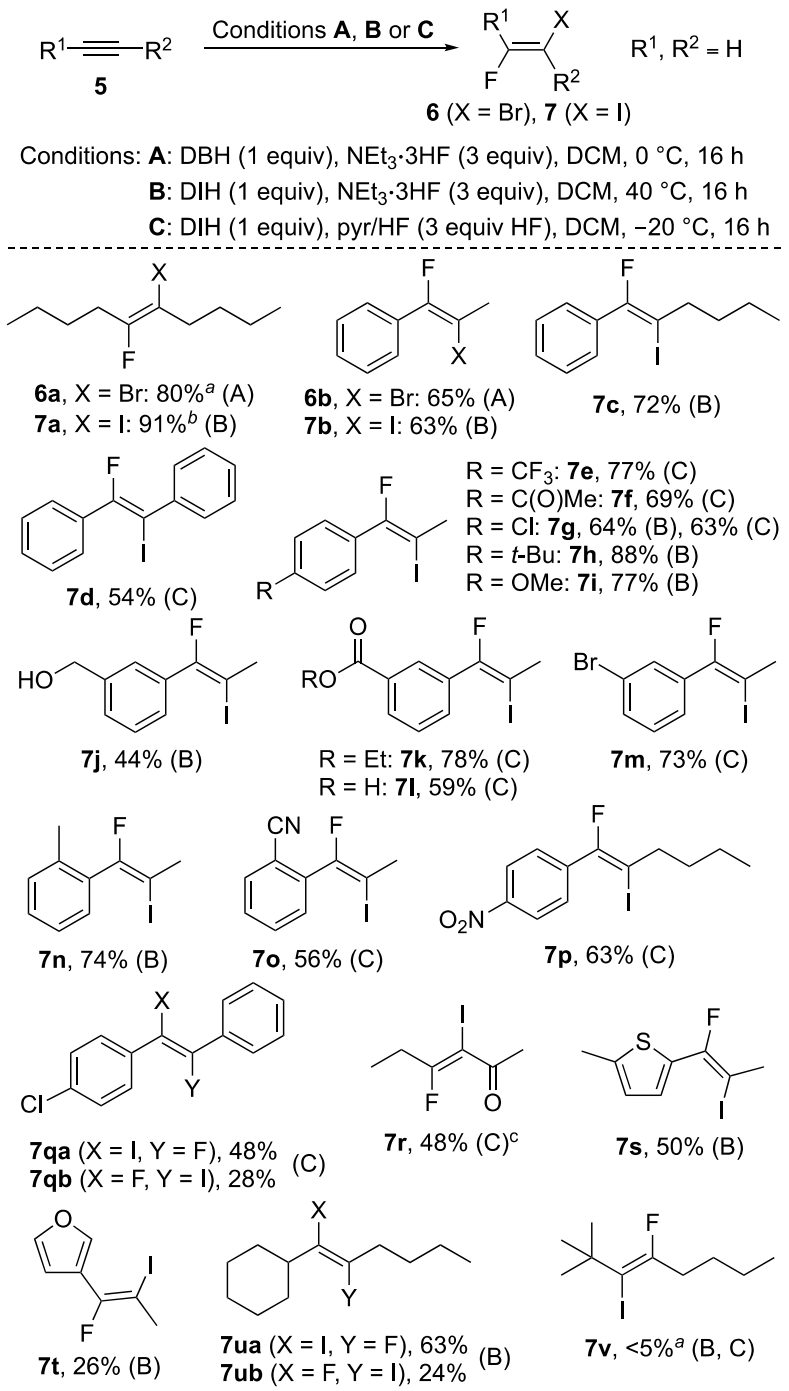

Conditions used are shown in parentheses. aYield determined by ${ }^{19} \mathrm{~F}$ NMR (hexafluorobenzene as internal reference). ${ }^{\mathrm{b}} 93 \%$ on $5 \mathrm{mmol}$ scale. cReaction at rt using pyr/HF (4 equiv HF).

Next, we examined the substrate scope for the single and double iodofluorination of terminal alkynes (Table 3). Good yields were obtained with unfunctionalized alkyl and aryl substrates 8a-8d (Table 3, entries 1-4), chloro- and cyano-substituted compounds $\mathbf{8 e}$ and $\mathbf{8 f}$ (Table 3, entries 5 and 6) as well as electron poor alkyne $\mathbf{8 i}$ (Table 3, entry 9). Alkyne 8g bearing a carboxylic acid functionality gave lower yields especially in the mono iodofluorination (Table 3, entry 7). For the mono iodofluorination of 4-Ph- and 4OMe-substituted phenylacetylenes $\mathbf{8 h}$ and $\mathbf{8 j}$, conditions $C$ only gave trace amounts of the desired products, whereas conditions B resulted in yields of $35 \%$ and $12 \%$, respectively
(Table 3, entries 8 and 10). Likewise, double iodofluorination gave $17 \%$ (10h) and a trace amount (10j) of the desired products, respectively. Products 10 bearing the 1,1-diiodo2,2-difluoroethyl functionality are rare, and accessed from the reaction of 1-hexyne or phenylacetylene with IF. 3 These products hold great potential as versatile intermediates, for example, for subsequent use in olefinations under Takai's conditions ${ }^{17}$ or via reaction with $\alpha$-sulfinyl carbanions, ${ }^{18}$ as well as double functionalization with a Grignard ${ }^{19}$ or organozinc ${ }^{20}$ reagent followed by quenching with an electrophile. The $(E)$-configuration of $\mathbf{7} \mathbf{b}$ and $\mathbf{9 d}$ was unambiguously confirmed using NOESY and ${ }^{19} \mathrm{~F}-{ }^{1} \mathrm{H}$ HOESY NMR experiments. ${ }^{21}$

Table 3. Substrate scope for the single and double iodofluorination of internal alkynes.

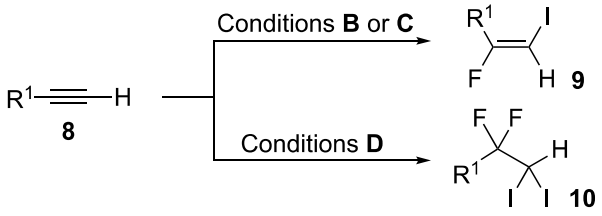

Conditions: B: DIH ( 1 equiv), NEt $3 \cdot 3 \mathrm{HF}$ (3 equiv), DCM, $40{ }^{\circ} \mathrm{C}, 16 \mathrm{~h}$
C: DIH ( 1 equiv), pyr/HF ( 3 equiv HF), DCM, $-20^{\circ} \mathrm{C}, 16 \mathrm{~h}$
D: DIH (1 equiv), pyr/HF (9 equiv HF), DCM, $-20{ }^{\circ} \mathrm{C}, 16 \mathrm{~h}$

\begin{tabular}{|c|c|c|c|}
\hline entry & substrate & $\mathbf{9}^{a}[\%]$ & $1^{a}[\%]$ \\
\hline 1 & & $74(C)$ & $80(D)$ \\
\hline 2 & & $43(C)$ & 42 (D) \\
\hline 3 & & $54(\mathrm{C})$ & 87 (D) \\
\hline 4 & & 78 (C) & $53(\mathrm{D})$ \\
\hline 5 & & $53(\mathrm{C})$ & 59 (D) \\
\hline 6 & & $74(C)$ & 78 (D) \\
\hline 7 & & 37 (C) & 57 (D) \\
\hline 8 & & 35 (B) & $17(\mathrm{D})$ \\
\hline 9 & & $68(C)$ & $76(\mathrm{D})$ \\
\hline 10 & & $12^{b}(\mathrm{~B})$ & $<5^{b}(\mathrm{D})$ \\
\hline
\end{tabular}

aConditions are shown in parentheses. bYield determined by ${ }^{19} \mathrm{~F}$ NMR (hexafluorobenzene as internal reference).

Iodofluoroalkenes are useful products for the preparation of highly substituted fluoroalkenes as they are amenable to Suzuki, Sonogashira or Ullmann-type cross couplings 
(Scheme $3 \mathrm{~A}$ ). ${ }^{21}$ This chemistry was applied to the preparation of the fluorinated tamoxifen derivative 11, a compound shown to exhibit higher growth inhibition against four tested human cancer cell lines compared to the parent compound. ${ }^{22}$ Applying our methodology, $\mathbf{7} \mathbf{d}$ was prepared and subsequently coupled to boronic acid $\mathbf{1 2}$ to afford $\mathbf{1 1}$ in $48 \%$ overall yield. This two linear steps synthesis constitutes a significant improvement from the original six-step procedure, for which no overall yield was provided (Scheme 3B). ${ }^{22}$

Scheme 3. Cross-coupling reactions with $7 \mathbf{a}(\mathrm{A})$, and twostep synthesis of the fluorinated tamoxifen 11 from alkyne 5d (B).

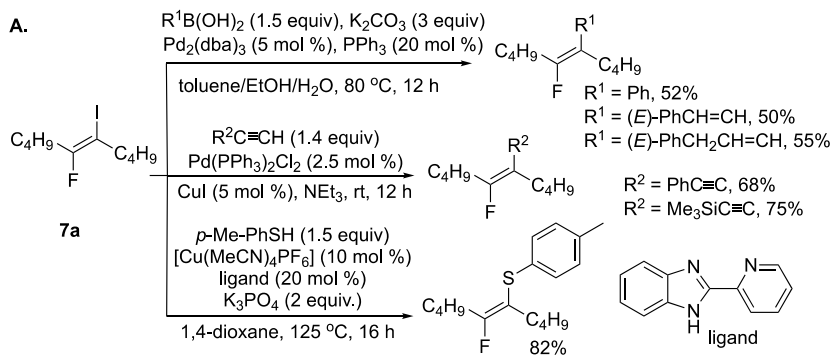

B.

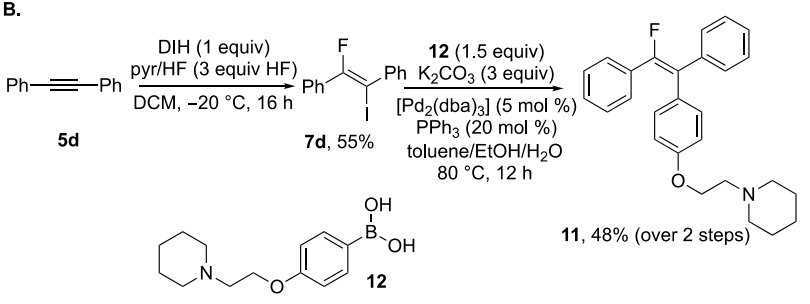

In conclusion, we have developed synthetic protocols enabling controlled iodofluorination of internal and terminal alkynes relying on the unique reactivity of the DIH/"HF" system. Our method for single iodofluorination tolerates a wide range of functionalities and has successfully been performed on gram-scale. It allowed facile access to a potent fluorinated tamoxifen derivative in two steps from commercially available starting materials. We have also developed a highly efficient strategy for double iodofluorination using the entire iodine content of DIH.

\section{ASSOCIATED CONTENT}

\section{Supporting Information}

The Supporting Information is available free of charge on the ACS Publications website. Experimental procedures, optimization tables, characterization data, and ${ }^{1} \mathrm{H},{ }^{13} \mathrm{C}$ and ${ }^{19} \mathrm{~F}$ spectra of all novel compounds (PDF).

\section{AUTHOR INFORMATION}

\section{Corresponding Author}

*Email: veronique.gouverneur@chem.ox.ac.uk

\section{ORCID}

Véronique Gouverneur: oooo-ooo1-8638-5308

\section{Notes}

The authors declare no competing financial interest.

\section{ACKNOWLEDGMENT}

Generous financial support by the EU (FP7-PEOPLE-2012ITN-RADIOMI-316882 to L.P.) is gratefully acknowledged. V.G. thanks the Royal Society for a Wolfson Research Merit Award (2013-2018).

\section{REFERENCES}

(1) (a) Olah, G. A.; Welch, J. T.; Vankar, Y. D.; Nojima, M.; Kerekes, I.; Olah, J. A. J. Org. Chem. 1979, 44, 3872. (b) Olah, G. A.; Nojima, M.; Kerekes, L. Synthesis 1973, 780. (c) Gregorcic, A.; Zupan, M. Bull. Chem. Soc. Jpn. 1987, 6o, 3083. (d) Eddarir, S.; Francesch, C.; Mestdagh, H.; Rolando, C. Bull. Soc. Chim. Fr. 1997, 134, 741. (e) Dear, R. E. A. J. Org. Chem. 1970, 35, 1703. (f) Dolenc, D.; Šket, B. Synlett 1995, 327.

(2) (a) Zupan, M. Synthesis 1976, 473. (b) Hara, S.; Yoshida, M.; Fukuhara, T.; Yoneda, N. Chem. Commun. 1998, 965. (c) Conte, P.; Panunzi, B.; Tingoli, M. Tetrahedron Lett. 2006, 47, 273.

(3) Rozen, S.; Brand, M. J. Org. Chem. 1986, 51, 222.

(4) Barluenga, J.; Rodríguez, M. A.; González, J. M.; Campos, P. J.; Asensio, G. Tetrahedron Lett. 1986, 27, 3303.

(5) Shellhamer, D. F.; Jones, B. C.; Pettus, B. J.; Pettus, T. L.; Stringer, J. M.; Heasley, V. L. J. Fluor. Chem. 1998, 88, 37.

(6) Li, Y.; Liu, X.; Ma, D.; Liu, B.; Jiang, H. Adv. Synth. Catal. 2012, 354, 2683.

(7) Ukigai, H.; Hara, S. Tetrahedron Lett. 2016, 57, 1379.

(8) (a) Emer, E.; Pfeifer, L.; Brown, J. M.; Gouverneur, V. Angew. Chem., Int. Ed. 2014, 53, 4181. (b) Tredwell, M.; Preshlock, S. M.; Taylor, N. J.; Gruber, S.; Huiban, M.; Passchier, J.; Mercier, J.; Genicot, C.; Gouverneur, V. Angew. Chem., Int. Ed. 2014, 53, 7751. (c) Khotavivattana, T.; Verhoog, S.; Tredwell, M.; Pfeifer, L.; Calderwood, S.; Wheelhouse, K.; Collier, T. L.; Gouverneur, V. Angew. Chem., Int. Ed. 2015, 54, 9991. (d) Verhoog, S.; Pfeifer, L.; Khotavivattana, T.; Calderwood, S.; Collier, T. L.; Wheelhouse, K.; Tredwell, M.; Gouverneur, V. Synlett 2016, 27, 25. (e) Preshlock, S.; Calderwood, S.; Verhoog, S.; Tredwell, M.; Huiban, M.; Hienzsch, A.; Gruber, S.; Wilson, T. C.; Taylor, N. J.; Cailly, T.; Schedler, M.; Collier, T. L.; Passchier, J.; Smits, R.; Mollitor, J.; Hoepping, A.; Mueller, M.; Genicot, C.; Mercier, J.; Gouverneur, V. Chem. Commun. 2016, 52, 8361. (f) Schuler, M.; Silva, F.; Bobbio, C.; Tessier, A.; Gouverneur, V. Angew. Chem., Int. Ed. 2008, 47, 7927.

(9) Hashmi, A. S. K.; Ramamurthi, T. D.; Rominger, F. J. Organomet. Chem. 2009, 694, 592.

(10) Akana, J. A.; Bhattacharyya, K. X.; Müller, P.; Sadighi, J. P. J. Am. Chem. Soc. 2007, 129, 7736.

(11) Okoromoba, O. E.; Han, J.; Hammond, G. B.; Xu, B. J. Am. Chem. Soc. 2014, 136, 14381.

(12) The multiplicity as well as coupling constants of the ${ }^{19} \mathrm{~F}$ NMR signals of 9a $(\mathrm{td}, J=22.6,17.8 \mathrm{~Hz})$ and $\mathbf{1 0 a}(\mathrm{td}, J=16.6,12.2 \mathrm{~Hz})$ were used to determine the regiochemistry of these products.

(13) Kirsch, P. Modern Fluoroorganic Chemistry: Synthesis, Reactivity, Applications, 2nd ed.; John Wiley \& Sons, Inc.: Weinheim, 2013.

(14) (a) Laurence, C.; Brameld, K. A.; Graton, J.; Le Questel, J.-Y.; Renault, E. J. Med. Chem. 2009, 52, 4073. (b) Liang, S.; Hammond, G. B.; Xu, B. Chem. Eur. J. 2017, 71, 17850.

(15) ${ }^{19}$ F NMR: $-66.3 \mathrm{ppm}(\mathrm{tq}, J=22.8,6.6 \mathrm{~Hz})$.

(16) ${ }^{19}$ F NMR: $-91.2 \mathrm{ppm}(\mathrm{t}, J=23.8 \mathrm{~Hz})(7 \mathrm{ua}) v s .-105.3 \mathrm{ppm}(\mathrm{d}, J=$ $28.9 \mathrm{~Hz})(\mathbf{7 u b})$

(17) Takai, K.; Nitta, K.; Utimoto, K. J. Am. Chem. Soc. 1986, 108, 7408. (18) (a) Abramovitch, A.; Varghese, J. P.; Marek, I. Org. Lett. 2004, 6, 621. (b) Abramovitch, A.; Marek, I. Eur. J. Org. Chem. 2008, 4924. (c) Varghese, J. P.; Knochel, P.; Marek, I. Org. Lett. 20oo, 2, 2849.

(19) Hoffmann, R. W.; Knopff, O.; Kusche, A. Angew. Chem., Int. Ed. 2000, 39, 1462.

(20) Shibli, A.; Varghese, J. P.; Knochel, P.; Marek, I. Synlett 20o1, 818. (21) See SI for details.

(22) Malo-Forest, B.; Landelle, G.; Roy, J. A.; Lacroix, J.; Gaudreault, R. C.; Paquin, J. F. Bioorg. Med. Chem. Lett. 2013, 23, 1712. 
